Bryant University

Bryant Digital Repository

Management Department Journal Articles

Management Faculty Publications and

Research

$5-2019$

\title{
Crafting better team climate: the benefits of using creative methods during team initiation
}

Dirk Primus

Bryant University, dprimus@bryant.edu

Crystal Jiang

Bryant University, cjiang1@bryant.edu

Follow this and additional works at: https://digitalcommons.bryant.edu/manjou

Part of the Business Administration, Management, and Operations Commons, and the Management Sciences and Quantitative Methods Commons

\section{Recommended Citation}

Primus, Dirk and Jiang, Crystal, "Crafting better team climate: the benefits of using creative methods during team initiation" (2019). Management Department Journal Articles. Paper 48. https://digitalcommons.bryant.edu/manjou/48

This Article is brought to you for free and open access by the Management Faculty Publications and Research at Bryant Digital Repository. It has been accepted for inclusion in Management Department Journal Articles by an authorized administrator of Bryant Digital Repository. For more information, please contact dcommons@bryant.edu. 


\title{
Crafting better team climate: the benefits of using creative methods during team initiation
}

\section{Dirk J. Primus* and Crystal X. Jiang}

\author{
Bryant University, \\ 1150 Douglas Turnpike, \\ Smithfield, RI 02917, USA \\ Email: dprimus@bryant.edu \\ Email: cjiang1@bryant.edu \\ *Corresponding author
}

\begin{abstract}
This study employs a mixed methods approach to investigate the effect of creative methods, the combinative use of model building and storytelling, during team initiation on team climate, a critical people-related factor in the management of collective innovation work. Qualitative analysis provides empirical evidence that creative methods benefit team initiation by raising participative confidence, engagement with the social environment as well as the team activities, friendly competition among team members, and by reducing fear of failure and habitual thinking. We also find support that the use of creative methods initiates and supports the development of positive team climate over the span of a team's life. A quantitative comparison with two control groups using the 14-item team climate inventory (TCI) 13 weeks after the team initiation indicates that the test group has significantly higher values in all dimensions of the TCI than the two control groups. Overall, this examination informs the work of innovation managers and scholars with vital insights about the effectiveness of using creative methods during team initiation.
\end{abstract}

Keywords: team climate; team building; creative methods; team initiation.

Reference to this paper should be made as follows: Primus, D.J. and Jiang, C.X. (2019) 'Crafting better team climate: the benefits of using creative methods during team initiation', Int. J. Technology Management, Vol. 79, Nos. 3/4, pp.299-321.

Biographical notes: Dirk J. Primus is an Assistant Professor in Management at Bryant University. His teaching and research draw from extensive experience (15 years) gained in various leadership positions in the life sciences industry. In his industry career, he worked for Johnson and Johnson, Fresenius ProServe, Life Sciences International Suisse and most recently for Pall Life Sciences. He holds a PhD in Business from Bentley University, an Executive MBA as well as postgraduate degrees in Microbiology and Chemical/Bioprocess Engineering. His published work on innovation appears in top-ranked periodicals like Technovation or the Creativity Research Journal and includes studies on the strategic alignment of product development and supply chain management, strategic resource allocation during epidemic growth periods and entry strategies for bottom of the pyramid (BOP) markets. His most recent research investigates the application of creative methods, such as model building and storytelling, in innovation work. 
Crystal X. Jiang is an Associate Professor of Management at Bryant University, RI, USA. Her research focuses on firms originated from emerging economies in capability-building, innovation strategy and cross-cultural management. Her research work has appeared in premier journals, including the Journal of Management, Journal of International Business Studies, Journal of World Business, Oxford Handbook of International Business, among others. She is an executive board member of the Academy of International Business US Northeast Chapter and an Associate Editor for the New England Journal of Entrepreneurship (NEJE).

This paper is a revised and expanded version of a paper entitled 'Crafting better team climate: the effects of using creative methods during team initiation' presented at ISPIM Innovation Conference, Vienna, 17-21 June 2017.

\section{Introduction}

People create new technologies more often through collective innovation work than as individuals [Buijs, (2007), p.206]. The most recent Product Development Management Association (PDMA) study by Markham et al. (2013) notes that "the use of teams is pervasive and systemic in product innovation" and find that "the best [firms] use cross-functional development teams significantly more than the rest". Correspondingly, there is a rapid increase in interest in people-related issues, such as participation and sharing in R\&D, innovation, and technology development (Järvenpää and Majchrzak, 2016; Ritala et al., 2015; Wendelken et al., 2014). The PDMA study further finds that teams in "the best [firms] have a higher sense of togetherness than the rest" and that "the best are more likely to facilitate internal collaboration via team building [than the rest]". Closely related, recent innovation research also emphasises the importance of team climate in product development projects (see Açıkgöz and Günsel, 2016). In accordance with prior work on team climate (Açıkgöz and Günsel, 2016; Anderson and West, 1996, 1998; Choi et al., 2003; Herman et al., 2008), we define it conceptually as a collective property of the team, representing "the shared positive perceptions and the atmosphere of interactions among members". To examine team climate empirically, following Anderson and West's (1998) work, we conceptualise team climate inventory (TCI) via four factors, namely, vision, participative safety, task orientation, and support for innovation. Mathisen et al. (2004) note the scientific quality of the TCI and its prevalence in the literature concerned with work environments conducive to innovation. Using the TCI, Strating and Niboer $(2009$, p.127) study healthcare quality improvement teams and note that "a team's innovativeness may be facilitated or hindered by the climate in the team". However, recent innovation research reports that "managers seem to lack an understanding of best practice elements of climate" and that "continued work on [this topic] is warranted" (Kahn et al., 2012). For that reason, team climate and its practice elements must be considered critical factors in the management of the creation of new technologies.

Anderson and West's (1998) work notes that team climate can be improved by team building and, conversely, that the TCI can be used to diagnose the effectiveness of team building. Team building is one of two team development interventions (Klein et al., 2009). The other team development intervention, team training, is skill or task focused, 
systematic, and features formal rehearsals of particular team skills. Team building practices, by contrast, are less systematic, less task focused and often come in the form of games, adventures, or exercises. In accordance with Klein et al. (2009) and, more recently, Shuffler et al. (2011), team building is defined as "a set of strategies designed to improve interpersonal relations, social interactions, and the achievement of goals" (p.368). Team building can occur in different phases of a team's life. In this paper, our focus is on the initiation meeting, when the team first convenes, because team initiation has been noted to be especially important in an innovation context and as a key concern of innovation team leaders [Buijs, (2007), p.206]. Gersick (1988, 1991) finds that behaviours and themes that dominate a period of inertial movement of the team are determined by the end of the first meeting. Accordingly, team initiation represents a critical point in a team's life, as it sets the direction for the first half of the team's tenure.

A novel, unconventional, and promising approach for team building or intervention to improve team climate is offered by the combination of building and sharing models, which we, in accordance with Gauntlett $(2007,2013)$, refer to as 'creative methods'. Model building in this context refers to the creation of physical objects by hand, using materials like toy building blocks, canvas, pictures, construction supplies, symbolic figures, or similar. Sharing in this context is accomplished by crafting of a compelling narrative about the model that relates to the vision of the individual or the team. Crafting a narrative is closely related to model building as it is "an act of pulling together different strands and elements into an order" [Gauntlett, (2007), p.167]. Conventional conceptualisations that relate climate of the social environment and creativity present positive climate as a key pre-requisite for individual creativity (e.g., Amabile, 1996). Contrary, yet complementary to this view, and similar to recent examinations by Açıkgöz and Günsel (2016), this study investigates the role of creative processes in the development of team climate.

Creative methods are known to stimulate intuition and imagination, and increase insight, leading to more novel and surprising solutions to problems (Gauntlett, 2007). In addition, a small collection of recent work posits that the use of creative methods in collective activities - as employed in the Lego serious play (LSP) process - has positive effects on participants that benefit team development (DeLarge, 2004; Hadida, 2013; Kristiansen and Rasmussen, 2014). The LSP process guides participants through a structured sequence of creating individual and shared haptic models from Lego bricks and storytelling with the aim to generate shared understanding in team activities and to enhance creativity in ideation exercises (Kristiansen and Rasmussen, 2014; Schulz et al., 2015). Accordingly, this investigation is concerned with the effect of everyday creative methods as a team building or intervention tool. It is important to note that the form of creative practices investigated in this study is different from cases of 'grand creativity' extreme occurrences of artistic or scientific revolutionary works that shifted or changed a whole domain of thinking - by the likes of Beethoven or Michelangelo. What we mean by creative methods is "people express[ing] themselves in non-traditional ways" through crafting models or stories (Gauntlett, 2007). Such "acts of creativity involve [...] a social dimension and connect us with other people" (Gauntlett, 2013), physically making an object helps team members to make sense of their social environment (Hadida, 2013), stories enhance the formation and function of a team (DeLarge, 2004) and thus, creative methods are expected to benefit team activities and team development (Gauntlett, 2007; Kristiansen and Rasmussen, 2014). However, robust scientific empirical evidence supporting the conjecture that creative methods can serve as a team building tool to 
benefit team development and, more specifically, team climate is sparse. Furthermore, while Klein et al.'s (2009) meta-analysis confirms that team building interventions generally improve process and affective outcomes, little is known about the mechanisms by which it works.

In sum, our study contributes to this special edition by investigating creative methods as an unconventional way to improve team climate, a critical people-related factor in technology management. To accomplish the goal of this research, we apply elements from a design thinking process and the LSP method that emphasise creative methods during team initiation of an MBA cohort. Specifically, we study the effects of creative methods on individual team members and teams during a three-day team initiation activity. To empirically investigate conjectures from prior work on the effects of creative methods on team interactions as discussed in Section 2, our work focuses on the combinative use of building physical models and face-to-face storytelling as creative methods. We employ qualitative analysis to investigate conjectures about the effects of creative methods on participants in team activities. In doing so, our paper contributes to an emerging stream of work with an empirical examination of the effects of creative methods during team initiation. Further, we examine the impact of using creative methods during team initiation on team climate several weeks into the teams' life using a quantitative, survey-based comparison with two control groups of MBA students that were not exposed to creative methods-focused activities during their initiation. This is the first study that examines the relationship between creative methods during team initiation and the development of team climate in the long term, and addresses another gap in the body of knowledge on team building because most scholarly work is "limited to an isolated post-intervention measure of performance [and] there is a need to investigate the results of team building over the span of the team's life" (Klein et al., 2009).

\section{Theory on the effects of creative methods on team interactions}

As noted in the introduction, a small collection of recent research and practitioner work advocates the use of building physical models and face-to-face storytelling as a team building practice (DeLarge, 2004; Hadida, 2013; Kristiansen and Rasmussen, 2014; Schulz et al., 2015). Closely related, Gauntlett's $(2007,2013)$ work notes that the use of model building and storytelling improves the understanding of identities and helps individuals connect with other people. A brief review of this literature suggests that the use of creative methods during team activities has several specific effects on individual team members that benefit the development of positive shared perceptions and the atmosphere of interaction (team climate), as shown in Figure 1. As also illustrated in Figure 1, team climate can be determined empirically via the TCI and its four factors, vision, participative safety, task orientation, and support for innovation. Anderson and West's (1998, p.240) work defines vision as "an idea of a valued outcome which represents a higher order goal and a motivating force at work". "Participativeness and safety are characterized as a single psychological construct in which the contingencies are such that involvement in decision-making is motivated and reinforced while occurring in an environment which is perceived as interpersonally non-threatening". Task orientation is referred to as "a shared concern with excellence of quality of task performance in relation to shared vision or outcomes, characterized by evaluations, modifications, control systems and critical appraisals". And support for innovation is defined as "the 
expectation, approval, and practical support of attempts to introduce new and improved ways of doing things in the work environment". The ensuing discussion suggests that some effects of creative methods on individual team members contribute the development of specific factors of the TCI at the team level, while others benefit the overall team climate.

Figure 1 Effects of using creative methods on individual team members that benefit the development of positive shared perceptions and the atmosphere of interaction, team climate

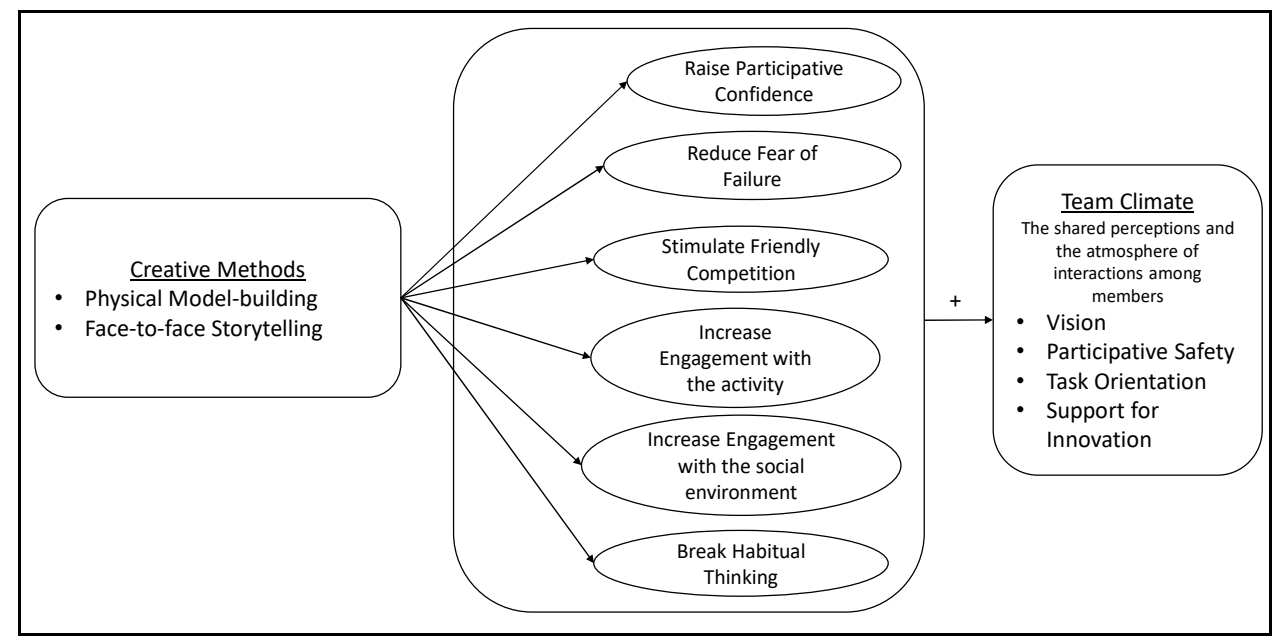

Firstly, existing work notes that creative methods can improve participative confidence. Accordingly, the use of model building and storytelling can change the course of team meetings, where a few participants dominate the meeting, while others have difficulties with expressing themselves or with getting sufficient 'airtime' (Kristiansen and Rasmussen, 2014). More specifically, creative methods help more hesitant individuals to express themselves, because model building provides the opportunity to communicate richer and different kinds of information than is possible through words alone (Hadida, 2013). Schulz et al. (2015, p.355) observe in two case studies about innovation teams that employed building of physical models and face-to-face storytelling that individual contributions were considered of equal value. Further, because creative methods shift the focal point of questioning from the person to the model and its story, they also reduce the fear of failure (Kristiansen and Rasmussen, 2014). Hadida (2013) observes that "[building models] allows [participants] to [...] share their ideas at work in a playful, non-judgmental and non-threatening environment" (Hadida, 2013). As a result, creative methods allow for a fuller understanding of another person's expressions and identity [Gauntlett, (2007), p.90]. In accordance with the conceptual definitions for the four factors of the TCI, we expect that increased participative confidence and reduced fear of failure in team members will benefit the development of participative safety and support for innovation at the team level, ultimately improving team climate. Moreover, using creative methods in a team setting stimulates a friendly or 'constructive competition' among members, thereby raising the commitment to the shared goals of the team [Gauntlett, (2007), p.134]. Consequently, we expect that friendly competition between team members raises the factor of task orientation at the team level. Correspondingly, 
Loewen and Loo (2004) find that better knowledge of individual characteristics and members showing their commitment to the team improve the development of team climate.

Another benefit of applying creative methods is increased engagement with the activity and the social environment. Creative methods increase the level of engagement with the activity across all participants, including more passive people. When people begin a creative process, like crafting a model, the activity often becomes autotelic - a condition where people do things to feel the experience more than to reach an end and without external motivation (Csikszentmihalyi, 2014). The creative processes 'evoke a feeling of joy' that comes directly from making and sharing models and stories (Gauntlett, 2013). Such condition of people immersed in a creative process has been described as a form of 'fascinated engagement' (Gauntlett, 2007). Further, 'through making things and sharing them [...] we increase our engagement with our social and physical environments" [Gauntlett, (2013), p.2]. Engaging with a narrative (a story) is "a way of developing understanding, and moving oneself from relative ignorance toward an informed engagement with experience" [Gauntlett, (2007), p.167]. As a result, as team members from different cultures and with different experiences "perform together, they form common stories [...] that create new cultures" [DeLarge, (2004), p.76]. Thus, our review indicates that the use of creative methods increases engagement and benefits the development of shared positive perceptions as well as the atmosphere of interactions, overall team climate.

A final benefit of using creative methods is their propensity to break habitual thinking. A "characteristic of habitual behavior [in groups is that] members do not actively assess the situation or evaluate alternative behavioral choice" [Gersick and Hackman, (1990), p.72]. Habitual individual thinking can thus be a strong impediment to the development of positive interactions and shared perceptions, climate, in a team. Correspondingly, Kristiansen and Rasmussen (2014) note that creative processes help to break individual habitual thinking and positively impact the development of a shared vision and decision-making of groups. Consequently, we expect that breaking habitual thinking of individual team members contributes to the development of the factor vision at the team level and, thus, benefits team climate.

In sum, recent work concerned with the use of building physical models and face-to-face storytelling indicates that the effects of using creative methods on team members in meetings include increases in participative confidence, friendly competition among team members, engagement with the activity, and the social environment, as well as decreases in the fear of failure and habitual thinking. However, a robust scientific study supporting these conjectures does not exist. Accordingly, our paper contributes to this emerging stream of work with an empirical examination of the effects of creative methods during team initiation. Furthermore, our review supports that the use of creative methods initiates and supports the development of positive team climate. This is the first study that examines the relationship between creative methods during team initiation and the development of team climate over the span of a team's life.

\section{Methods}

In this study, we employ a mixed methods approach by combining quantitative survey analysis with qualitative directed-content analysis, to investigate the effects of using 
creative methods during team initiation on team climate. Mixed methods are emerging in innovation management research and are generally considered to be more robust than quantitative or qualitative analysis alone (Amabile et al., 2005; Grimpe et al., 2017; Perks and Roberts, 2013). In our specific research design, we use quantitative survey data to understand and quantify the basic form of the relationship between creative methods and the dimensions of the TCI, by testing the significance of differences between a test group and two control groups. Additionally, we use qualitative directed-content analysis to investigate conjectures about the effects of creative methods on individuals in team activities, afford explanations for quantitative results (Grimpe et al., 2017), detect temporal patterns within the exercise (Amabile et al., 2005) and provide additional insight into context (Grimpe et al., 2017).

\subsection{Participants and control groups}

The participants and control groups in this study are MBA students. Recent research on creative team process has shown that empirical results from student samples can inform the work of innovation managers in the design thinking and creativity domain (Amabile et al., 2005; Bissola et al., 2014; Seidel and Fixson, 2013; Yang and Hung, 2015). With respect to generalisability of findings from a student sample, Chiocchio and Essiembre (2009, p.386) note that "teams of undergraduate and graduate students are as real as any other type of teams". Correspondingly, Bissola et al. (2014, p.380) note that findings and insights from comparing worker samples with student samples in the area of product development, group decisions, and workplace behaviour converge. Moreover, studies on MBA students provide the advantage of close comparability of key variables that affect the relationship between team building and outcomes, which is a frequent shortfall of previous work (Klein et al., 2009). For example, teams of MBA students within one program are very similar in size, level of interdependence, task environments, meeting frequency, and contact time, which are difficult to accomplish in firm settings [Bissola et al., (2014), p.380].

The students are part of three different cohorts: one full-time cohort $(\mathrm{C}-1)$ and two part-time cohorts (C-2 and C-3). The full-time cohort, C-1, completes its MBA program in one-year, divided into three trimesters. $\mathrm{C}-1$ is comprised of 26 (73\% male and $27 \%$ female) students. Their mean age at the time of data collection was 23.8 years $(\mathrm{SD}=3.3$ years) with 0.8 years of average job experience. The part-time cohorts complete their MBA program in a two-year and four semester format. C-2 is comprised of $28(50 \%$ male and $50 \%$ female) students. Their mean age at the time of data collection was 26.6 years $(\mathrm{SD}=5.4$ years) with 4.4 years of average job experience. $\mathrm{C}-3$ is comprised of $31(61 \%$ male and $39 \%$ female) students. Their mean age at the time of data collection was 28.4 years $(\mathrm{SD}=5.8$ years $)$ with 7.6 years $(\mathrm{SD}=6.1$ years $)$ of average job experience.

In order to assess whether full-time and part-time MBA cohorts are comparable in terms of physical proximity, contact frequency, and interference from work commitments as factors that could affect team development during the period of observation, we collected data about their place of residence and employment during the MBA program. In the full-time cohort $\mathrm{C}-1,15.4 \%$ of students lived on campus and since they were not assigned to the same team, their campus residency would not have exerted an impact on their community life and relationship building. Further, $70.8 \%$ of $\mathrm{C}-1$ had permanent part-time jobs or comparable commitments as student athletes. In the part-time cohort 
C-2, all students had permanent jobs and no student lived on campus, but $18.5 \%$ of students worked on campus. In the part-time cohort C-3, all students had permanent jobs and no student lived on campus, but $16.1 \%$ of students worked on campus. In sum, the share of MBA students that were consistently present on campus, because they permanently live or work there is comparable across the three cohorts, whereas the share of students with permanent commitments to a job or as an athlete is higher in the two part-time cohorts than in the full-time cohort.

All three cohorts participated in a 3-day boot-camp program in week 1 of their MBA studies. C-1 is divided into five teams, C-2 has five teams, and C-3 has six teams. Team members in $\mathrm{C}-1$ were selected in a voluntary process. These teams participated in an extensive creative methods team exercise during their initiation phase in the boot-camp. Team members in C-2 and C-3 were selected by faculty and administrators, using the results from a Myers-Briggs Type Indicator (MBTI), which has been widely used for team formation in educational environments (e.g., Amato and Amato, 2005; Varvel et al., 2004). The MBTI indicator was also a widely used instrument to examine personality types and their potential influence on team effectiveness in academia and industry (e.g., Coe, 1992). These students participated in a Business Simulation Game (BSG) as a team exercise during their initiation phase, which did not include any creative methods. Over the course of a 13-week trimester, MBA students worked in their cohort teams on a number of assignments and team projects in at least three courses.

Team climate develops over time, requiring newly formed teams to have reached semi-permanent or permanent state, and related theory identifies the necessary conditions to allow for shared perceptions and climate to develop (Loewen and Loo, 2004):

- individuals must interact

- individuals must have one or more common goal

- individuals must experience task interdependence.

Accordingly, all three cohorts and their teams fulfil the minimal conditions for team climate to developafter they have reached permanent state, which prior empirical work places at three weeks into the teams' life (Loewen and Loo, 2004).

\subsection{Process and materials used for C-1 team initiation}

Team initiation for C-1 took place in a three-day boot-camp in week 1 of the MBA studies. The process for this boot-camp also included sessions that focused on general orientation, as well as refreshers on fundamentals in several core business subjects. The main team activity for the boot-camp was an extended team exercise, which emphasised the deliberate and combinative use of model building and storytelling.

Models can be any object of thought, however, in our study they were physical objects, constructed by hand with Lego bricks, Play-Doh, as well as from basic arts and crafts supplies. We do not anticipate that the effects of creative methods are exclusive to these materials. However, we avoided using other materials, such as wet clay modelling or pencil drawing for practical reasons and to prevent the feeling that participants need to be artistically talented or get their hands dirty (Hadida, 2013).

Teams were formed in the morning of day 1 and the challenge for the exercise was introduced right after the midpoint of day 1 . To ensure that students adopt creative methods and engage in 'designerly thinking', which entails 'identifying the views of all 
participants', we selected a "wicked problem [...], a class of social systems problems with a fundamental indeterminacy without a single solution and where much creativity is needed" as the challenge (Buchanan, 1992; Johansson-Sköldberg et al., 2013). Accordingly, the challenge for the teams was to "think and design a conceptual business model that exploits the opportunities associated with urban transportation in the mega-cities of the 21 st century". Immediately afterward, the teams were given a brief introduction to the tenets of design theory (see Beckman and Barry, 2007; Buchanan, 1992; Carlgren et al., 2016; Johansson-Sköldberg et al., 2013), and more specifically, the application of crafting models and stories in solving complex business problems (see Kristiansen and Rasmussen, 2014).

To allow for sufficient reflective time during the process, which Csikszentmihalyi (1996) refers to as 'underground' incubation, the exercise was divided in six parts, which were interspersed with sessions that focused on general orientation, as well as refreshers on fundamentals in several core business subjects. The process used for the exercise is shown in Figure 2.

Figure 2 The process used for the exercise focused on model building and storytelling

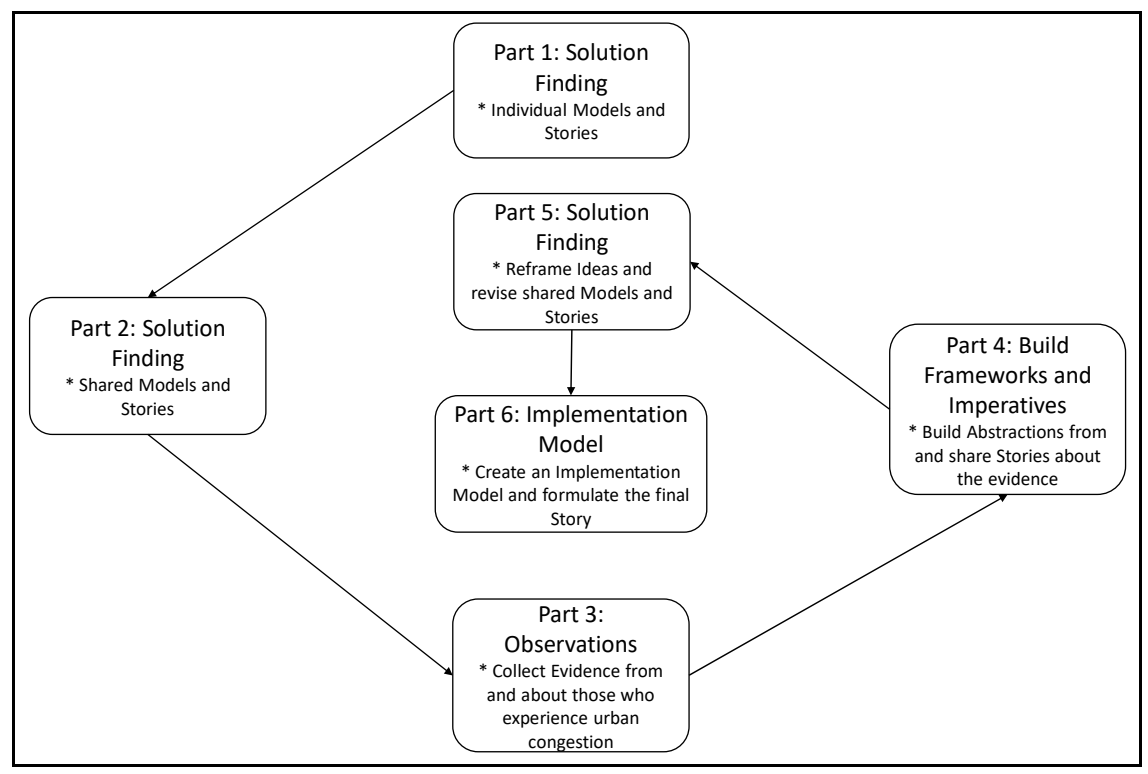

Each team was matched with facilitators from faculty and MBA alumni, whose role it was to:

a make sure that the intended process was followed

b that the teams were kept moving when they showed signs of getting stuck (Beckman and Barry, 2007).

One student noted in his/her reflections after the boot-camp:

"If our team were to run into an issue that we were unable to solve or were unsure about, we still had the ability to reach out to a professor or MBA graduate for assistance and direction." 
In part 1, participant teams were given one LSP starter kit per team and each team member was asked to build an individual model of their first idea. Accordingly, we initiated the process cycle with solution finding (Beckman and Barry, 2007). The teams were asked to not have a discussion about their individual ideas before they started building. Next, each member shared the 'story' of their model. Facilitators ensured that every person got sufficient 'airtime,' while other team members were encouraged to ask questions that focused on the model and the story, rather than the person.

In part 2, teams were asked to create a shared model of their individual ideas. Facilitators ensured that at least one feature from each individual model was incorporated in the shared model. When the first version of the shared model was created, teams were given basic Play-Doh kits, as well as miscellaneous arts and crafts supplies to expand and build the environment of their shared models. In part 3, the process cycle was moved to observations and teams were instructed to use the resources of the university to collect evidence from and about those, who experience urban congestion. For part 4, the teams were invited back into their team rooms to share stories and build abstractions of frameworks and imperatives that reflected the outcomes of their research (Beckman and Barry, 2007). In part 5, the teams were then asked to reframe their idea and revise their shared model, based on the frameworks and imperatives for their design. In part 6, the teams formulated the final story of their idea, including a preliminary implementation plan for the business design. Again, facilitators played a vital role in this stage, ensuring that the intended process was followed and that the team members were kept in a state of 'flow' by challenging questions (when boredom set in) or by coaching (when anxiety developed).

At the end of the exercise, teams presented their final model and story to the other teams, facilitators, selected faculty, and administrators of the MBA program. The teams were limited in their options to present, as standard tools, such as PowerPoint, Prezi, or similar applications were excluded from this part of the exercise. After the boot camp, the teams of C-1 were not exposed to any further team development interventions until the quantitative TCI survey was administered.

\subsection{Process used for $C-2$ and $C-3$ team initiation}

As for C-1, team initiation for C-2 and C-3 took place in a three-day boot-camp in week 1 of the MBA studies. The process for this boot-camp also included sessions focused on general orientation, as well as refreshers on fundamentals in several core business subjects. The main team activity for the boot-camp was an online business simulation game (BSG). This activity did not include any deliberate use of model building or storytelling. After their boot camp, the teams of C-2 and C-3 were not exposed to any team development interventions until the quantitative TCI survey was administered.

\section{Analyses}

As noted earlier in Section 3, our research design employs a combination of qualitative directed content analysis and quantitative survey analysis. Qualitative directed content analysis is used to validate the hypothesised immediate effects of creative methods on the individual participants shown in Figure 1, as well as to identify unexpected themes and temporal patterns, which cannot be accomplished with a quantitative analysis alone. 
Quantitative survey analysis complements the qualitative findings by quantifying the long-term effect of creative methods on team climate. The quantitative analysis allows to test for statistical significance of the differences between the test group and the control groups, which is not possible with a qualitative approach alone. Both analytical approaches are described in detail in the next paragraphs.

\subsection{Qualitative analysis}

Similar to Loewen and Loo (2004), we used qualitative content analysis to validate existing theory about the effects of creative methods on individuals and teams. At the end of the exercise, participants were invited to describe their experience during the exercise in the presence of their cohort and were recorded on video. In addition, we asked each participant to provide written, individual, and confidential responses to the following questions:

1 What is the most important takeaway for you from this exercise?

2 How has the experience changed you? How has the experience changed your team? In what way?

3 Which part of the experience surprised you, went against your own intuition/experience, or challenged you? How did you overcome all the identified issues?

In total, their responses resulted in approximately 9,000 words of data, which were analysed using a directed content analysis approach, as described by Hsieh and Shannon (2005). Specifically, we used the six indicators of participative safety, increased engagement with the activity and the social environment, reduced fear of failure, change of habitual thinking, and friendly competition from existing theory about the consequences of employing creative methods in team activities. Based on detailed operational definitions for the six indicators, four researchers coded phrases from the anonymised data into the six categories by highlighting text passages with pre-defined colours. The inter-coder reliability (ICR) was calculated for two sample indicators in accordance with Campbell et al. (2013) and was found to be $71 \%$ and $78 \%$, respectively. Subsequently, the researchers identified data that does not fit the categories, but provided additional insight into context or revealed temporal patterns.

\subsection{Survey timing and method}

To capture contrasts in the levels of team development, we employed the concept of team climate, as originally developed by Anderson and West $(1996,1998)$. Their instrument, the TCI, has subsequently been applied and validated by a number of scholars in a wide range of settings (e.g., Agrell and Gustafson, 1994; Brodbeck and Maier, 2001; Mathisen et al., 2004; Ragazzoni et al., 2002). The original instrument includes 61 items (Anderson and West, 1998), thus requiring large sample sizes to allow for significance testing. More recently, other researchers have applied and validated a short version of the TCI which will allow for smaller sample sizes (Kivimaeki and Elovainio, 1999; Strating and Niboer, 2009). After the teams of C-1 and C-2 had reached permanent state, at the end of their first 13-week semester, each individual from C-1, C-2 and C-3 completed an electronic version of a short TCI survey, adopted from Strating and Niboer (2009). 
At the time of the survey, C-1 teams had interacted for 4 months and had completed a total of 13 course credits together. C-2 teams had also interacted for 4 months and had completed a total of 7 course credits together. C-3 teams had interacted for 16 months and had completed a total of 25 course credits together. Figure 3 shows the timeline of treatments and analyses for each cohort as a fraction of courses completed and program time completed. Respondents answered 14 items (Table 2) which were presented in seven-point Likert-scales, anchored in strongly agree (7), neither agree nor disagree (4), and strongly disagree (1). The survey was administered electronically at the beginning of a regular class and on the same day for all three cohorts.

Figure 3 The timeline of treatments and analyses for each cohort as a fraction of courses completed and program time completed

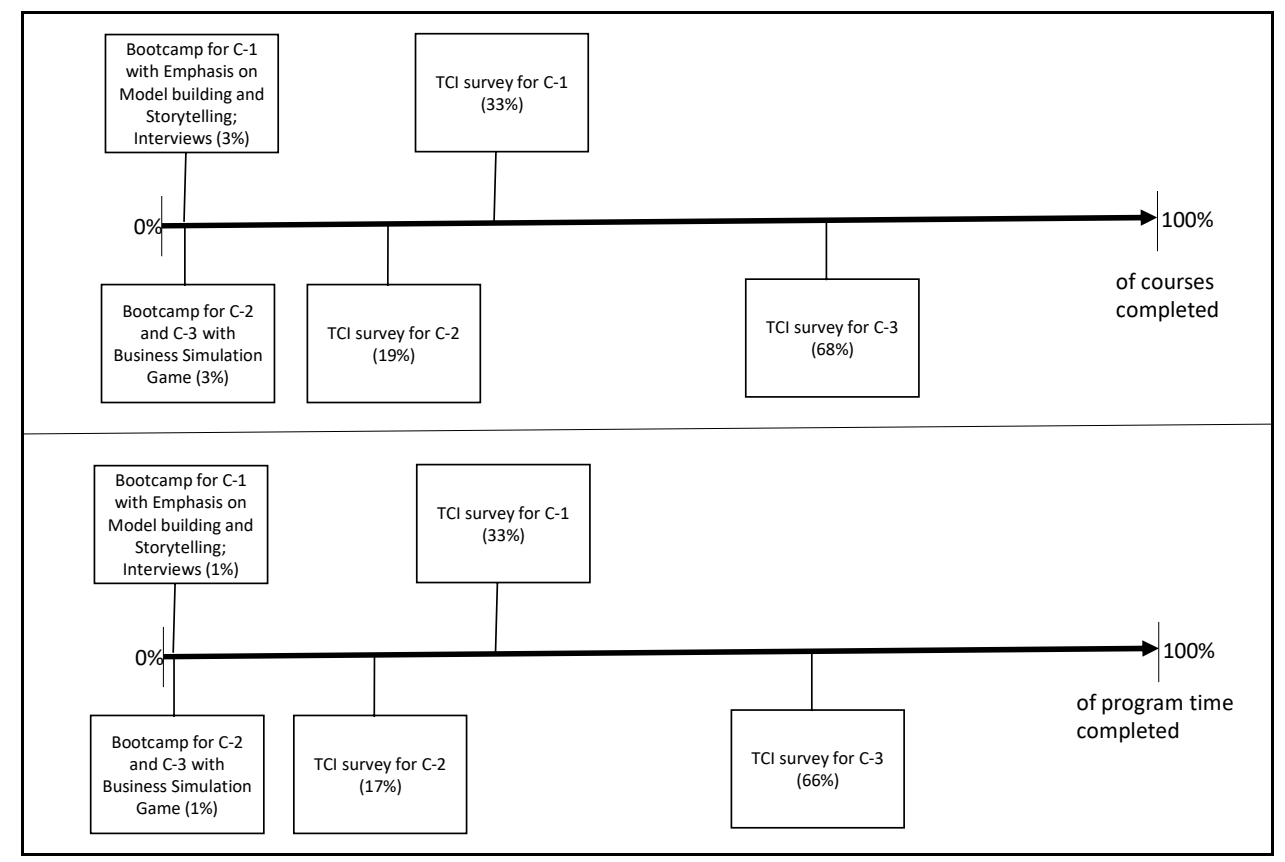

\section{Results and discussion}

\subsection{Results of directed content analysis and discussion}

As a first result, we saw that individuals can be overly accustomed to working and solving problems on their own. One participant reflects on her/his habitual behaviour prior to the exercise as follows:

"I never enjoyed working in a group as an undergrad or in high school. I was always too paranoid to trust my partner to get their share of the work done so I ended up doing it all on my own”. 
Another participant notes:

"It is difficult for me to accept ideas from others because I do find myself 'putting my head down and driving with a full head of steam' unaware and unaccepting of what other team members find important."

Table 1 Results of directed content coding of written reflections and interviews from C-1

\begin{tabular}{|c|c|}
\hline $\begin{array}{l}\text { Expected effects on } \\
\text { participants in team activity } \\
\text { (frequencies for categories } \\
\text { are shown in parentheses) }\end{array}$ & Illustrative examples from Reflections and Interviews \\
\hline \multirow[t]{2}{*}{ Reduced fear of failure (11) } & $\begin{array}{l}\text { "I was surprised how wordless model building led to idea } \\
\text { generation. Almost every model I have ever built has been the } \\
\text { result of planning; here the building led to planning and } \\
\text { strategy. Being able to experiment without fear of failure } \\
\text { allowed me to be more creative". }\end{array}$ \\
\hline & $\begin{array}{l}\text { "I am no longer afraid to work in groups in this program and } \\
\text { look forward to the comradery of the teams I will be a part of". }\end{array}$ \\
\hline \multirow[t]{2}{*}{ Increased engagement (10) } & $\begin{array}{l}\text { "This experience changed our team because it allowed our } \\
\text { small band of acquaintances to work effectively and efficiently } \\
\text { on the project but also grew into a team that will last well past } \\
\text { the MBA program. This gave us bonding time and the ability to } \\
\text { make true friends of our group". }\end{array}$ \\
\hline & $\begin{array}{l}\text { "Everyone became excited about the idea which motivated us to } \\
\text { continue our research even after the other team left. Overall, I } \\
\text { am more than pleased with my team's work and dedication } \\
\text { throughout the entire design thinking project". }\end{array}$ \\
\hline \multirow[t]{2}{*}{$\begin{array}{l}\text { Friendly competition - } \\
\text { contribution and } \\
\text { commitment (4) }\end{array}$} & $\begin{array}{l}\text { "I was surprised by the level of investment everyone was } \\
\text { willing to put into this project and by how well my team } \\
\text { worked together". }\end{array}$ \\
\hline & $\begin{array}{l}\text { "The part that surprised me the most was the commitment from } \\
\text { everyone in the [event].[...] [The exercise] challenged me to } \\
\text { match and exceed that energy of my classmates". }\end{array}$ \\
\hline \multirow[t]{3}{*}{$\begin{array}{l}\text { Increased participative } \\
\text { confidence (10) }\end{array}$} & $\begin{array}{l}\text { "This exercise brought out the creative side in me that I thought } \\
\text { never existed. In my } 12 \text { years of work experience I never had } \\
\text { the opportunity to be a part of building a prototype - so this } \\
\text { experience really made me realize a new side of me". }\end{array}$ \\
\hline & $\begin{array}{l}\text { "The experience has changed me to become more confident in } \\
\text { myself and with the people in my group". }\end{array}$ \\
\hline & $\begin{array}{l}\text { "This experience gave me the opportunity to be more assertive } \\
\text { and speak my mind while in a group/team setting". }\end{array}$ \\
\hline \multirow[t]{2}{*}{$\begin{array}{l}\text { Change of habitual thinking } \\
\text { (6) }\end{array}$} & $\begin{array}{l}\text { "Throughout my educational career, I preferred working as an } \\
\text { individual over as a group. I prefer to do things on my own } \\
\text { schedule rather than on the schedule of other people. This } \\
\text { experience allowed me to successfully work with teammates to } \\
\text { come up with an interesting idea through a combined effort". }\end{array}$ \\
\hline & $\begin{array}{l}\text { "This challenged me to listen more and really share my role as } \\
\text { an innate leader with others. I found is to be better not to take } \\
\text { charge all the time as I normally try to do, and it worked out } \\
\text { excellently". }\end{array}$ \\
\hline
\end{tabular}


Table 1 Results of directed content coding of written reflections and interviews from C-1 (continued)

\begin{tabular}{|c|c|}
\hline \multicolumn{2}{|c|}{$\begin{array}{l}\text { Themes, indicating a relationship with the development of shared perceptions and positive } \\
\text { interactions, team climate }\end{array}$} \\
\hline $\begin{array}{l}\text { Team climate index - vision } \\
\text { (Q-4) }\end{array}$ & $\begin{array}{l}\text { "We are committed to the vision of this program, as well as } \\
\text { eager to learn". }\end{array}$ \\
\hline & $\begin{array}{l}\text { "As in working in a team I can see that everyone in the program } \\
\text { is dedicated to the same goals I have". }\end{array}$ \\
\hline $\begin{array}{l}\text { Team climate index - } \\
\text { participative safety (Q-7) }\end{array}$ & $\begin{array}{l}\text { "... since we trusted each other as a team we evaluated all the } \\
\text { options we could select, and ended up using none of our } \\
\text { original ideas". }\end{array}$ \\
\hline $\begin{array}{l}\text { Team climate index - task } \\
\text { orientation }(\mathrm{Q}-11)\end{array}$ & $\begin{array}{l}\text { "This experience changed our team from a much unorganized } \\
\text { group of individuals at the beginning, all shouting out different } \\
\text { ideas and not letting anyone have the floor at once, into an } \\
\text { organized group that was ready to pitch an idea in a } \\
\text { professional manner over the course of a couple days". }\end{array}$ \\
\hline $\begin{array}{l}\text { Team climate index - } \\
\text { support for innovation } \\
\text { (Q-14) }\end{array}$ & $\begin{array}{l}\text { "Being part of a cohesive and efficient team was not only } \\
\text { intellectually rewarding, but it was fun! Each of our team } \\
\text { members input was insightful and inspiring. In the future I will } \\
\text { be focusing on allowing and encouraging others to give input, } \\
\text { as well as being more concise in my own contributions". }\end{array}$ \\
\hline
\end{tabular}

Most importantly, our results from directed content analysis provide strong support for the expected effects of using creative methods on participants in the team activity, as shown in Table 1. The evidence identified by the analysts varied from single phrases or sentences to passages of multiple sentences. Interestingly, most comments that supported theory on the six hypothesised effects of creative methods were framed as a surprise or a challenge by our respondents (see Table 1). For example, respondents specifically noted how they were surprised by the level of contribution and commitment that resulted from a friendly competition within the teams. Moreover, it is specifically noted in our responses that the use of creative methods not only increased participative confidence and reduced the fear of failure, but also challenged typically more dominant participants to change and reduce their habits of taking charge. The comments supporting increased engagement, participative confidence, and reduced fear also highlight a practical benefit of the use of creative methods in the context of innovation. Specifically, our respondents noted that they became very excited with their ideas and they experienced elevated levels of self-perceived creativity, which should benefit the outcomes of innovation (Amabile, 2012).

In addition, we found evidence that the use of creative methods initiated and supported the development of shared perceptions and positive interactions among team members. As illustrated in Table 1, we found strong evidence that links the use of creative methods with specific items of the four factors vision (Q-4), participative safety (Q-7), task orientation (Q-11), and support for innovation (Q-14) of the TCI. Although our qualitative analysis revealed a very positive climate in teams, not every item in the TCI was supported by our qualitative data. This is not surprising, however, given that the full development of team climate requires interaction and task interdependency over time (Loewen and Loo, 2004). 
Table 2 Results of pairwise comparisons for $14 \mathrm{TCI}$ items and latent constructs of cohorts 1, 2 and 3 (see online version for colours)

\begin{tabular}{|c|c|c|c|c|}
\hline & & $\begin{array}{l}\text { Cohort } 1 \\
(N=24)\end{array}$ & $\begin{array}{l}\text { Cohort } 2 \\
(N=25)\end{array}$ & $\begin{array}{l}\text { Cohort } 3 \\
(N=28)\end{array}$ \\
\hline \multicolumn{2}{|c|}{ Team climate inventory $(1)\left(1>2,3^{*}\right)$} & 0.78 & -0.07 & -0.61 \\
\hline \multicolumn{2}{|c|}{ Vision $(1)\left(1>2,3^{*}\right)$} & 0.72 & -0.01 & -0.61 \\
\hline Q1 & $\begin{array}{l}\text { The objectives set by your team are achievable. } \\
\text { (1) }\left(1>2,3^{*}\right)\end{array}$ & 6.65 & 6.00 & 6.00 \\
\hline Q2 & $\begin{array}{l}\text { Your team's objectives are clearly understood by } \\
\text { other members of the team. (1) }\left(1>2^{*}, 2>3^{*}\right)\end{array}$ & 6.48 & 5.78 & 4.75 \\
\hline Q3 & $\begin{array}{l}\text { You are in agreement with these objectives. } \\
(1)\left(1>2,3^{* *}\right)\end{array}$ & 6.57 & 5.88 & 5.39 \\
\hline Q4 & $\begin{array}{l}\text { The team's objectives contribute to the overall goals } \\
\text { set for the MBA program }(1)\left(1>2^{* *}, 2>3^{* *}\right)\end{array}$ & 6.74 & 6.08 & 5.36 \\
\hline \multicolumn{2}{|c|}{ Participative safety $(1)\left(1>2,3^{*}\right)$} & 0.62 & 0.01 & -0.54 \\
\hline Q5 & $\begin{array}{l}\text { We have a 'we are in it together' attitude (1) } \\
\left(1>2^{*}, 2>3^{*}\right)\end{array}$ & 6.70 & 5.96 & 5.21 \\
\hline Q6 & $\begin{array}{l}\text { People keep each other informed about work-related } \\
\text { issues in the team }(1)\left(1>2^{* *}, 2>3^{*}\right)\end{array}$ & 6.78 & 5.80 & 4.57 \\
\hline Q7 & $\begin{array}{l}\text { People feel understood and accepted by each other } \\
\left(1>3^{*}\right)\end{array}$ & 6.30 & 5.56 & 5.36 \\
\hline Q8 & $\begin{array}{l}\text { There are real attempts to share information } \\
\text { throughout the team }\left(1>3^{*}\right)\end{array}$ & 6.30 & 5.56 & 5.36 \\
\hline \multicolumn{2}{|c|}{ Task orientation $(1)\left(1>2,3^{*}\right)$} & 0.68 & -0.13 & -0.47 \\
\hline Q9 & $\begin{array}{l}\text { Team members are prepared to question the basis of } \\
\text { what the team is doing. (1) }\left(1>2,3^{* *}\right)\end{array}$ & 6.35 & 5.92 & 5.43 \\
\hline Q10 & $\begin{array}{l}\text { The team critically appraises potential weaknesses in } \\
\text { what it is doing in in order to achieve the best } \\
\text { possible outcome }\left(1>2^{*}, 3^{* *}\right)\end{array}$ & 6.52 & 5.64 & 5.11 \\
\hline Q11 & $\begin{array}{l}\text { Members of the team build on each other's ideas in } \\
\text { order to achieve the best possible outcome }\left(1>3^{*}\right)\end{array}$ & 6.57 & 5.88 & 5.50 \\
\hline \multicolumn{2}{|c|}{ Support for innovation $(1)\left(1>2,3^{*}\right)$} & 0.76 & -0.14 & -0.52 \\
\hline Q12 & $\begin{array}{l}\text { People in this team are always searching for fresh, } \\
\text { new ways of looking at problems }(1)\left(1>2,3^{* *}\right)\end{array}$ & 6.48 & 5.08 & 4.36 \\
\hline Q13 & $\begin{array}{l}\text { In this team we take the time needed to develop new } \\
\text { ideas }\left(1>2,3^{* *}\right)\end{array}$ & 6.30 & 4.96 & 4.64 \\
\hline Q14 & $\begin{array}{l}\text { People in the team cooperate in order to help develop } \\
\text { and apply new ideas }\left(1>2^{*}, 3^{* *}\right)\end{array}$ & 6.48 & 5.48 & 4.96 \\
\hline
\end{tabular}

Notes: '(1) Levene's test indicated unequal variances across groups; supplemental Kruskal-Wallis tests are performed Significant differences between test groups are explained in parentheses.

* Group means are significantly different at $\mathrm{p}<.05$.

**Group means are significantly different at $\mathrm{p}<.01$.

Model test: pillai's trace: 0.692; F:2.307; SIG.: 0.001 . 
Our findings also include some interesting temporal patterns within the exercise. For example, a reflection by a participant that is presented as an example for reduced fear of failure in Table 1 also suggests the reversal of the typical temporal sequence of first planning and then building. In addition, aquote from a participant that is presented as an example for the development of task orientation in Table 1 indicates that this dimension developed rather quickly, over two to three days.

The coding activity also provided additional insights into context in form of unexpected themes that did not fit the theory discussed in Section 2, but indicated a positive relationship with the development of team climate. For example, one participant emphasised the team related benefits of focusing on model building instead of relying on technology during the exercise:

"[The exercise] changed the team, because we didn't rely on technology so we could have more time to think of the model."

This comment suggests that the use of collaborative technology in team work, while efficient in some ways, may be distractive, time consuming, and detrimental to the development of team climate. This aspect could be investigated in future work by comparing digital model building with manual model building.

Other participants noted the positive effects of working under time constraints:

"I liked that we didn't have too much time to work on this project, because [...] it forces you to step up to think creatively and also be critical of what you are doing."

This observation suggests that time constraints foster participation by individuals and have a positive effect on team climate in terms of task orientation.

\footnotetext{
"Because we were all together and in that fast-paced environment, there was no time to worry about anything other than the project. Which, I thought was good and everyone was very committed."
}

Accordingly, this observation indicates that time constrains have a positive effect on team climate in terms of vision. The impact of time constraints could also be investigated in future work in research designs that apply varying levels of time constraints to different test groups.

\subsection{Structural analysis of team climate survey data}

To enable a comparison between the test group and the two control groups at the level of the latent constructs of the TCI, we performed confirmatory factor analysis (CFA), using partial least squares modelling (PLS), as described in Hair et al. (2010). Using PLS supports our research design, because it allows for sample sizes much smaller than generally accommodated by other techniques, such as structural equation modelling [Hair et al., (2010), p.740]. Our results from validating the model are shown in Table 3. The results are in line with prior results by Strating and Niboer (2009) and provide evidence for adequate factor loadings $(>0.7 ; 0.808-0.9$ ), good model fit (SRMR $<0.08$ ), as well as sufficient convergent validity (AVE $>0.5)$ and internal consistency $(\mathrm{CR}>0.7)$ of all the latent constructs [Hair et al., (2010), p.673]. The factor scores for vision, participative safety, task orientation, support for innovation, as well as the overall team climate derived from the modelling were subsequently used in the comparison of test group and control groups. 
Table 3 Results of structural analysis of 14 TCI items and latent constructs

\begin{tabular}{cccc}
\hline & Factor loading & $\begin{array}{c}\text { Composite } \\
\text { reliability (CR) }\end{array}$ & $\begin{array}{c}\text { Average variance } \\
\text { extracted (AVE) }\end{array}$ \\
\hline Vision & 0.808 & 0.911 & 0.720 \\
Q1 & 0.860 & & \\
Q2 & 0.872 & & \\
Q3 & 0.854 & & 0.755 \\
Q4 & & & \\
Participative safety & 0.901 & & \\
Q5 & 0.819 & & 0.861 \\
Q6 & 0.877 & & \\
Q7 & 0.876 & & \\
Q8 & & 0.949 & \\
Support for innovation & 0.871 & & 0.814 \\
Q9 & 0.893 & & \\
Q10 & 0.911 & & \\
Q11 & & & \\
Task orientation & 0.912 & & \\
Q12 & 0.942 & & \\
Q13 & 0.930 & & \\
Q14 & & & \\
TCI & & & \\
Model fit: SRMR $=0.019$ & & & \\
\hline
\end{tabular}

\subsection{Survey results and discussion}

Table 2 shows the mean scores for the 14 items and the latent constructs of the short TCI for all three cohorts. The results from comparisons using ANOVA and MANOVA between the three cohorts are shown in parentheses. A first important finding is that the mean scores for all items are above the mid-point of the scale (4) for all three cohorts, suggesting that team climate was positive across the cohorts. This finding is consistent with reports from prior studies, using the full 44-item instrument (Loewen and Loo, 2004), as well as the 14-item version of the TCI instrument (Kivimaeki and Elovainio, 1999; Strating and Niebor, 2009). The results further indicate that there are no significant differences between $\mathrm{C}-2$ and $\mathrm{C}-3$ at the level of the first order and second constructs of the TCI, providing support that the two control groups who were not subjected to creative methods during team initiation are not different in terms of their vision, participative safety, task orientation, support for innovation, as well their overall team climate. By contrast, data from $\mathrm{C}-1$, who were subjected to an exercise that emphasised creative methods during team initiation showed significantly higher levels than C-2 and C-3 in all first order and second constructs of the TCI. This result complements our qualitative findings about the development of positive team climate during the exercise by confirming that team climate in $\mathrm{C}-1$ remains positive in the long run and that the team climate in the test group is significantly higher than in the two control groups. 
Comparing C-1 with C-2 and C-3 at the item level, every difference was statistically significant, except for the contrast with C-2 on items Q-7, Q-8, and Q-11. This result is somewhat surprising, since we found specific evidence supporting a positive impact on items Q-7 and Q-11 in C-1 immediately after the creative methods exercise during the boot-camp. A possible explanation is that those dimensions of team climate are the least durable and to uphold the positive effects on Q-7 and Q-11 observed immediately after the exercise, a repeated intervention with creative methods exercises may be necessary. Comparing C-2 and C-3 at the item level, differences in Q-2, Q-4, Q-5, and Q-6 were statistically significant with higher scores for C-2. SinceC-3 worked together for a longer period than $\mathrm{C}-2$, a possible explanation for this result is that these indicators of team climate diminish over time, which again would make a case for repeated intervention with creative methods.

\section{Limitations and future research}

This study advances the understanding of the link between team climate and the use of creative methods during team initiation, but also suggests the need for continued investigation. A first limitation of this study is that it does not examine the effects of using creative methods in a firm context and this should be investigated in future studies. However, recent work examining creative processes has shown that results derived from student samples can inform innovation management practitioners, when the design is best supported by a student sample (Seidel and Fixson, 2013) and when the study approximates the real work environment as close as possible (Bissola et al., 2014). This study benefits from a research setting that is difficult to accomplish in a firm context in terms of the pre-requisites for the development of team climate (Loewen and Loo, 2004). Specifically, interaction time and frequency, goal commonality as well as levels of task interdependence are typically not as consistent in real work environments as they are among cohort teams in an MBA program. Secondly, the study also benefits from a comparative analysis of teams that had minimal interaction before they were initiated. This condition is also difficult to achieve in a firm context. Thirdly, the boot-camp setting approximated real life innovation workshop settings very closely.

Another potential limitation stems from comparing full-time MBA students in the test cohort with two cohorts that were part-time MBA students. One may conjecture that part-time students get less involved than full-time students, because of differences in contact frequency and physical proximity. Furthermore, earlier work by Hancock (1998) notes that work commitments, which can be more prevalent for part-time students, may interfere with team development. To our knowledge, there is no empirical evidence that team climate differs between full-time and part-time MBA teams, and prior empirical work on team interactions (e.g., Gómez et al., 2000) treats part-time and full-time MBAs as homogenous subsets. In this present study, presence on campus as proxy for physical proximity and contact frequency was comparable between full-time and part-time MBA students, as shown in Section 3. The share of students with work commitments, which could interfere with team development, was moderately higher in the part-time cohorts than in the full-time cohort. For that reason, the observed difference in team climate between full-time and part-time MBA cohorts may not be fully due to the treatment with creative methods in the initiation phase. Future work could expand this work and 
compare the effects of creative methods on team climate for groups with different levels of physical proximity, contact frequency and non-team-related commitments.

As noted in Sections 1 and 2, this study focused on specific creative methods, building physical models and face-to-face storytelling. Future work could examine the effect of building models and sharing stories in virtual spaces, and contrast them with our results. Our qualitative results suggest a positive impact on team climate from working under constraints, in terms of technology and time. Our design emphasised a low-tech approach and stringent time constraints, but our design did not test the impact of varying time constraints or levels of technology use on team climate, which could be investigated in future work.

A further potential limitation is the single quantitative measurement of team climate using the TCI thirteen weeks after the creative methods exercise. Future work could benefit from a second TCI measurement closer to the exercise, right after the teams have reached semi-permanent or permanent state, which prior work marks at approximately three weeks into the teams' life.

Our work highlighted the importance of facilitation, yet our study did not test the effect of different facilitators with different facilitation styles on creative methods exercises and team climate. Future research could examine comparable settings with different facilitators comparatively.

\section{Conclusions and implications}

In this study, we examined the combinative use of model-building and storytelling during team initiation as an unconventional way to improve team climate, a critical people-related factor in technology management. We found robust empirical support for the expected effects of the combinative use of building physical models and face-to-face storytelling on individual team members and their contribution to the development of team climate. It should be noted that although we treated the effects of creative methods on individual team members separately for analytical reasons (see Figure 1), they may also interact with each other. It is, for example, likely that increased engagement with the activity will raise participative confidence and vice versa. Our work contributes to an emerging stream of work on the positive effects of creative methods on individual participants in team activities by developing and validating the model with six theorised effects shown in Figure 1. Furthermore, our qualitative analysis revealed that the combinative use of building physical models and face-to-face storytelling via its effects on individual team members contributes to the development of all four factors of the TCI. Thus, our results expand and extend findings and insights from recent qualitative empirical work on the combination of manual model building and storytelling in a firm context (Schulz et al., 2015). Specifically, our study provides evidence that the combinative use of building physical models and face-to-face storytelling has additional effects on participants and affects team climate dimensions other than vision. Our qualitative evidence, collected from the test group immediately after the initiation meeting with the creative methods exercise, suggests that participative safety, task orientation and support for innovation started to develop even before the teams had reached permanent state. In addition, our results revealed some temporal patterns in the effects of creative methods and indicate that constraints in terms of timing and technology can have a positive effect on the development of positive team climate. With 
respect to technology constraints, recall that the participants from the test group $(\mathrm{C}-1)$ were constrained to use the materials from their creative methods exercise instead of technologies to create and present their conceptual ideas, while the control groups (C-2 and C-3) were not constrained in such manner. The latter finding corroborates existing conceptual work on the role of constraints in innovation by Johnson (2013), who contends based on case evidence that resource constraints produce proximity and a sense of collaboration, proximity leads to faster feedback and ultimately drives innovation. However, to our knowledge time and technology constraints have not been considered by prior empirical work on team climate. Furthermore, our results from comparative analyses support that positive team climate can be enhanced and sustained for several weeks into the teams' life by using creative methods during team initiation. Therefore, our work contributes to the team building literature by investigating the effectiveness of creative methods beyond an isolated post-intervention measure.

In terms of managerial implications, people who create new technologies, specifically innovation team leaders, can benefit from our findings about using creative methods during team initiation. For example, our work highlights that creative processes and team processes are not independent and innovation team leaders should consider creative methods exercises as an unconventional way to initiate their teams in order to enhance the climate within and, by extension, the innovativeness of their teams. For example, our results provide evidence that members of teams, which employ creative methods during their initiation period become more committed to the team's goals and exhibit higher creative confidence, as suggested previously by Kristiansen and Rasmussen (2014). Even during later stages of their teams' tenure, innovation team leaders can employ the six indicators shown in Table 1 as a complementary tool to the TCI to diagnose innovation teams at the individual level for the need of an intervention. In case of deficits in the six indicators and the TCI, they can employ the six indicators of the effects on individual members as a training tool, similar to Loewen and Loo (2004), and prescribe a creative methods exercise as an intervention. Moreover, the observed positive effect of time and technology constraints on team climate shows that innovation team leaders should consider challenging their teams by constraining their time and support with technology, as proposed by Johnson (2013). Finally, innovation team leaders can benefit from our insights, because the use of creative methods may lessen the tension (or contradictions) between generative mode and focusing mode of managing teams, and thereby the burden on the innovation team leader to act as a 'controlled schizophrenic' [Buijs, (2007), p.209]. For example, our findings indicate that the use of creative methods fosters the simultaneous development of vision, as well as on goal management (task orientation). In sum, our findings indicate that innovation leaders should consider the combinative use of model building and storytelling as an important practice element of team climate and, thus, a factor that can benefit the management of the creation of new technologies.

\section{References}

Açıkgöz, A., and Günsel, A. (2016) 'Individual creativity and team climate in software development projects: the mediating role of team decision processes', Creativity and Innovation Management, Vol. 25, No. 4, pp.445-463.

Agrell, A. and Gustafson, R. (1994) 'The team climate inventory (TCI) and group innovation: a psychometric test on a Swedish sample of work groups', Journal of Occupational and Organizational Psychology, Vol. 67, No. 2, pp.143-151. 
Amabile, T. (2012) Componential Theory of Creativity, Working Paper 12-096, Harvard Business School, Boston, MA.

Amabile, T.M. (1996) Creativity and Innovation in Organizations, Vol. 5, Harvard Business School, Boston.

Amabile, T.M., Barsade, S.G., Mueller, J.S. and Staw, B.M. (2005) 'Affect and creativity at work', Administrative Science Quarterly, Vol. 50, No. 3, pp.367-403.

Amato, C.H., and Amato, L.H. (2005) 'Enhancing student team effectiveness: application of Myers-Briggs personality assessment in business courses', Journal of Marketing Education, Vol. 27, No. 1, pp.41-51.

Anderson, N.R. and West, M.A. (1996) 'The team climate inventory: development of the TCI and its applications in teambuilding for innovativeness', European Journal of Work and Organizational Psychology, Vol. 5, No. 1, pp.53-66.

Anderson, N.R., and West, M.A. (1998) 'Measuring climate for work group innovation: development and validation of the team climate inventory', Journal of Organizational Behavior, Vol. 19, No. 3, pp.235-258.

Beckman, S.L. and Barry, M. (2007) 'Innovation as a learning process: embedding design thinking', California Management Review, Vol. 50, No. 1, pp.25-56.

Bissola, R., Imperatori, B. and Colonel, R.T. (2014) 'Enhancing the creative performance of new product teams: an organizational configurational approach', Journal of Product Innovation Management, Vol. 31, No. 2, pp.375-391.

Brodbeck, F.C. and Maier, G.W. (2001) 'The team climate inventory (TCI) for innovation: a psychometric test on a German sample of work groups', Zeitschrift Fur Arbeits-Und Organisationspsychologie, Vol. 45, No. 2, pp.59-73.

Buchanan, R. (1992) 'Wicked problems in design thinking', Design issues, Vol. 8, No. 2, pp.5-21.

Buijs, J. (2007) 'Innovation leaders should be controlled schizophrenics', Creativity and Innovation Management, Vol. 16, No. 2, pp.203-210.

Campbell, J.L., Quincy, C., Osserman, J. and Pedersen, O.K. (2013) 'Coding in-depth semistructured interviews: Problems of unitization and intercoder reliability and agreement', Sociological Methods \& Research, Vol. 42, No. 3, pp.294-320.

Carlgren, L., Elmquist, M. and Rauth, I. (2016) 'The challenges of using design thinking in industry - experiences from five large firms', Creativity and Innovation Management, Vol. 25, No. 3, pp.344-362.

Chiocchio, F. and Essiembre, H. (2009) 'Cohesion and performance: a meta-analytic review of disparities between project teams, production teams, and service teams', Small Group Research, Vol. 40, No. 4, pp.382-420.

Choi, J.N., Price, R.H. and Vinokur, A.D. (2003) 'Self-efficacy changes in groups: effects of diversity, leadership, and group climate', Journal of Organizational Behavior, Vol. 24, No. 4, pp.357-372.

Coe, C.K. (1992) 'The MBTI: Potential uses and misuses in personnel administration', Public Personnel Management, Vol. 21, No. 4, pp.511-522.

Csikszentmihalyi, M. (1996) Flow and the Psychology of Discovery and Invention, 1st ed., Harper Collins, New York.

Csikszentmihalyi, M. (2014) Flow and the Foundations of Positive Psychology, 1st ed., Springer, Dordrecht.

DeLarge, C.A. (2004) 'Storytelling as a critical success factor in design processes and outcomes', Design Management Review, Vol. 15, No. 3, pp.76-81.

Gauntlett, D. (2007) Creative Explorations: New Approaches to Identities and Audiences, 1st ed., Routledge, Cambridge.

Gauntlett, D. (2013) Making is Connecting, 1st ed., John Wiley \& Sons, New York.

Gersick, C.J. (1988) 'Time and transition in work teams: toward a new model of group development', Academy of Management Journal, Vol. 31, No. 1, pp.9-41. 
Gersick, C.J. (1991) 'Revolutionary change theories: a multilevel exploration of the punctuated equilibrium paradigm', Academy of Management Review, Vol. 16, No. 1, pp.10-36.

Gersick, C.J. and Hackman, J.R. (1990) 'Habitual routines in task-performing groups', Organizational Behavior and Human Decision Processes, Vol. 47, No. 1, pp.65-97.

Gómez, C., Kirkman, B.L. and Shapiro, D.L. (2000) 'The impact of collectivism and in-group/out-group membership on the evaluation generosity of team members', Academy of management Journal, Vol. 43, No. 6, pp.1097-1106.

Grimpe, C., Sofka, W., Bhargava, M. and Chatterjee, R. (2017) 'R\&D, marketing innovation, and new product performance: a mixed methods study', Journal of Product Innovation Management, Vol. 34, No. 3, pp.360-383.

Hadida, A.L. (2013) 'Let your hands do the thinking! Lego bricks, strategic thinking and ideas generation within organizations', Strategic Direction, Vol. 29, No. 2, pp.3-5.

Hair, J.F., Anderson, R.E., Babin, B.J. and Black, W.C. (2010) Multivariate Data Analysis: A Global Perspective, 7th ed., Pearson, Upper Saddle River.

Hancock, T. (1998) 'The new MBA: flies in the paradigm', Business Horizons, Vol. 41, No. 4, pp.41-45.

Herman, H.M., Dasborough, M.T. and Ashkanasy, N.M. (2008) 'A multi-level analysis of team climate and interpersonal exchange relationships at work', The Leadership Quarterly, Vol. 19, No. 2, pp.195-211.

Hsieh, H.F. and Shannon, S.E. (2005) 'Three approaches to qualitative content analysis', Qualitative Health Research, Vol. 15, No. 9, pp.1277-1288.

Järvenpää, S.L. and Majchrzak, A. (2016) 'Interactive self-regulatory theory for sharing and protecting in interorganizational collaborations', Academy of Management Review, Vol. 41, No. 1, pp.9-27.

Johansson-Sköldberg, U., Woodilla, J. and Çetinkaya, M. (2013) 'Design thinking: past, present and possible futures', Creativity and Innovation Management, Vol. 22, No. 2, pp.121-146.

Johnson, W. (2013) 'Why innovators love constraints', Harvard Business Review, February, pp.1-4.

Kahn, K.B., Barczak, G., Nicholas, J., Ledwith, A. and Perks, H. (2012) 'An examination of new product development best practice', Journal of Product Innovation Management, Vol. 29, No. 2, pp.180-192.

Kivimäki, M. and Elovainio, M. (1999) 'A short version of the team climate inventory: development and psychometric properties', Journal of Occupational and Organizational Psychology, Vol. 72, No. 2, pp.241-246.

Klein, C., DiazGranados, D., Salas, E., Le, H., Burke, C.S., Lyons, R. and Goodwin, G.F. (2009) 'Does team building work?', Small Group Research, Vol. 40, No. 2, pp.181-222.

Kristiansen, P. and Rasmussen, R. (2014) Building a Better Business using the Lego Serious Play Method, 1st ed., John Wiley \& Sons, New Jersey.

Loewen, P. and Loo, R. (2004) 'Assessing team climate by qualitative and quantitative approaches: Building the learning organization', The Learning Organization, Vol. 11, No. 3, pp.260-272.

Markham, S.K. and Lee, H. (2013) 'Product development and management association's 2012 comparative performance assessment study', Journal of Product Innovation Management, Vol. 30, No. 3, pp.408-429.

Mathisen, G.E., Einarsen, S., Jorstad, K. and Bronnick, K.S. (2004) 'Climate for work group creativity and innovation: Norwegian validation of the team climate inventory (TCI)', Scandinavian Journal of Psychology, Vol. 45, No. 5, pp.383-392.

Perks, H. and Roberts, D. (2013) 'A review of longitudinal research in the product innovation field, with discussion of utility and conduct of sequence analysis', Journal of Product Innovation Management, Vol. 30, No. 6, pp.1099-1111. 
Ragazzoni, P., Baiardi, P., Zotti, A.M., Anderson, N. and West, M. (2002) 'Research note: Italian validation of the team climate inventory: a measure of team climate for innovation', Journal of Managerial Psychology, Vol. 17, No. 4, pp.325-336.

Ritala, P., Olander, H., Michailova, S. and Husted, K. (2015) 'Knowledge sharing, knowledge leaking and relative innovation performance: an empirical study', Technovation, Vol. 35, pp.22-31.

Schulz, K.P., Geithner, S., Woelfel, C. and Krzywinski, J. (2015) 'Toolkit-based modelling and serious play as means to foster creativity in innovation processes', Creativity and Innovation Management, Vol. 24, No. 2, pp.323-340.

Seidel, V.P. and Fixson, S.K. (2013) 'Adopting design thinking in novice multidisciplinary teams: the application and limits of design methods and reflexive practices', Journal of Product Innovation Management, Vol. 30, No. S1, pp.19-33.

Shuffler, M.L., DiazGranados, D. and Salas, E. (2011) 'There's a science for that: team development interventions in organizations', Current Directions in Psychological Science, Vol. 20. No. 6, pp.365-372.

Strating, M.M. and Nieboer, A.P. (2009) 'Psychometric test of the team climate inventory-short version investigated in Dutch quality improvement teams', BMC Health Services Research, Vol. 9, No. 1, p.126.

Varvel, T., Adams, S.G., Pridie, S.J. and Ruiz Ulloa, B.C. (2004) 'Team effectiveness and individual Myers-Briggs personality dimensions', Journal of Management in Engineering, Vol. 20, No. 4, pp.141-146.

Wendelken, A., Danzinger, F., Rau, C. and Moeslein, K.M. (2014) 'Innovation without me: why employees do (not) participate in organizational innovation communities', $R \& D$ Management, Vol. 44, No. 2, pp.217-236.

Yang, J-S. and Hung, H.V. (2015) 'Emotions as constraining and facilitating factors for creativity: companionate love and anger', Creativity and Innovation Management, Vol. 24, No. 2, pp.217-230. 